\title{
Silencing Climate Change in Utah Through Extremist Rhetoric and Stakeholder Processes: A Critical Discourse Analysis
}

\author{
Grace Elizabeth Bjarnson ${ }^{1}$ \\ ${ }^{1}$ City and Metropolitan Planning Department, University of Utah, Salt Lake City, Utah, United States \\ Correspondence: Grace Elizabeth Bjarnson, City and Metropolitan Planning Department, University of Utah, \\ Salt Lake City, Utah, United States. E-mail: urbangraceb@yahoo.com
}

Received: March 6, 2013 Accepted: April 1, 2013 Online Published: April 16, 2013

doi:10.5539/jsd.v6n5p50 URL: http://dx.doi.org/10.5539/jsd.v6n5p50

\begin{abstract}
This paper utilizes Critical Discourse Analysis (CDA) to explore the dimensions of domination and freedom within two significant public forums on climate change in Utah: (1) the resolution HJR 12 passed in the Utah State Legislature in 2010 and (2) the Blue Ribbon Committee on Climate Change (BRAC) process organized in 2006. The resolution HJR 12 reflects an extremist or inflammatory rhetoric point of view, while BRAC presents itself as a beacon of bureaucratic rationality, efficiency, and hierarchy. Forums such as these are force-feeding Americans subtly and not so subtly with divisive discourse and restrictive visions that pollute American politics and weaken the nation's capacity to address and solve its most challenging problems. HJR 12 exemplifies the role interpretive control plays in silencing those who disagree. The BRAC process illustrated how bureaucracy and rationalization may constrain future vision and action, reinforce current power structures, and encourage extreme rhetoric further down the road. This analysis uncovers the idealization of rational power underlying both forums. This idealization creates an unstable ground where powerplays, poorly disguised as rational policy making, dominate while silencing other voices. Scholars, government bureaucracies at all levels, and the American public wishing to deal with today's complex challenges must purposefully address destructive assumptions associated with idealized rational processes, while recognizing the important role uncertainty, values, worldviews, and interests play in encouraging or discouraging policy change.
\end{abstract}

Keywords: climate change, extremist rhetoric, stakeholder processes, critical discourse analysis, cap and trade, politics, values, Utah

\section{Introduction}

Many have said that in a democracy controversy is healthy. It is reasonable to assume that complex issues such as health care, immigration and military intervention will not lend themselves to simple, consensual solutions (Gutmann, 2007). Michael Heazle explains that, "States pursuing their respective national interests are constantly engaging in a broad range of policy issues 'where facts are uncertain, values in dispute, stakes high and decisions urgent'. Moreover, they do so in an anarchical environment shaped by perceptions of power and self-interest where intangibles dominate and distinctions between 'reliable knowledge' and 'speculation' seldom exist (Heazle, 2010, p 12)”. One such issue in the United States is climate change and the associated push to diversify the energy industry (green energy). Within Utah this debate has received a large amount of attention from both the Democratic and Republican Parties. This paper will focus on two significant public forums on climate change that have taken place within the last 7 years in Utah: (1) the bill HJR 12 passed in the State Legislature and (2) the Blue Ribbon Committee on Climate Change (BRAC) process conducted several years earlier.

American citizens are starting to see a link between divisive discourse that pollutes our politics and the political system's diminished capacity to address intelligently and solve our most challenging problems (Gutmann, 2007). The passage of resolution HJR 12 in the Utah State Legislature in February of 2010 is a perfect illustration of how inflammatory discourse silences a large portion of the public and hamper the ability to move forward in finding solutions. Within this resolution, the House of Representatives accused climate change science and scientists as being part of a conspiracy. However, many are unaware of how bureaucratic control over stakeholder committee processes may also silence, limit movement forward, and open a space for future inflammatory discourse. Governor Jon M. Huntsman organized the Blue Ribbon Committee on Climate Change 
(BRAC) on August 25, 2006. Its purpose was to provide a forum where representatives from government, industry, environment, and the community could have a productive dialogue regarding energy options available in Utah to reduce greenhouse gas (GHG) emissions. Many considered this process to be a huge step forward. But a closer look at the process brings to light many subtle ways of silencing and limiting future possibilities. Both the political forum filled with spectacle as well as the bureaucratic governmental forum filled with rationality, efficiency, and hierarchy provide specific structures of rhetoric that support those in power and the status quo while silencing in some degree those with less power.

I will be analyzing the public and bureaucratic forums through the lens of Critical Discourse Analysis (CDA). CDA explores the dimensions of domination and freedom within specific real-world contexts in all of its complexity. Through CDA I seek to uncover motivating worldviews, values, and assumptions that shape our society today, breaking open the subjective and intersubjective realms of reality that underlie our societies capacity to change. The two forums of discourse in question demonstrate how our public arenas have constrained us, often in ways that are virtually unnoticed. Lakoff highlights the power evident in order to silence others. "The ability of one party in a discourse to prevent another from fully participating (silencing) arises out of the disparate powers and roles of each, and contributes to the further unbalancing of those roles (Lakoff, 1995, p. 26)".

Since the meaning of silence is so ambiguous and can only be discerned through the understanding of the context in which it occurs, I start this paper by describing the circumstances and a brief history of the two forums of discourse. A comparison will then be made between these two forums and the types of silence they encourage. As I point out the silences or absences that are evident within these two forums, underlying idealized assumptions concerning each forum's legitimacy begin to appear. These unspoken views about knowledge, rationality, and power, and how they support the validity of these forums themselves end up encouraging the silencing of many. Despite the outward differences between these two forums both chose to silence the general public and their values, thus stymying the opportunity for deep dialog leading towards better decision-making.

\section{Resolution HJR 12}

In February 2010, Utah's House of Representatives, passed a resolution that implied climate change science is a conspiracy. The resolution also urged the United States Environmental Protection Agency (EPA) to stop all carbon dioxide reduction policies and programs. As a resolution, it holds no legal weight, but it sent a new message to those pushing clean energy in Utah and within the Federal Government. Previous to this action it was common for states to complain about the opposite situation - the EPA's inaction. One of the most famous of these cases (Massachusetts v. Environmental Protection Agency) took place in 2007. The Supreme Court ruled in favor of Massachusetts and 11 other states that claimed the EPA had the authority under the Clean Air Act to consider carbon dioxide and other greenhouse gasses (GHGs) as pollutants and could therefore regulate them (justice.gov).

The turn of events by the Utah State Legislature was just the beginning of an attack against the introduction of a national/international cap and trade program for greenhouse gas (GHG) emissions. Within a year of the passage of Utah's resolution, the Federal Government was experiencing one of the most sustained assaults on the environment ever. In the spring of 2011, environmental groups were expending all of their energy just stopping Congress from gutting the Clean Air Act. The atmosphere of skepticism brought on by the sudden rise of the Tea Party had encouraged the Republican Party to attack any hint of support in climate change regulation. By March of 2011, thirty-one Republicans on the House Energy And Commerce Committee -- the entire Republican contingency on the panel -- declined to vote in support of the very idea that climate change existed. Previous to this, some Republican representatives were willing to admit there was a problem. Some were even willing to provide solutions, now there was flat denial (McMorris-Santoro, 2011).

It is no surprise that this opposition to climate change regulations would initially rear its head in the Utah State Legislature, which has traditionally been controlled by the Republican Party. Much of the state's slow but steady progress on clean energy and climate change policies came under the leadership of former Republican Governor Huntsman, who resigned in 2009 to become U.S. ambassador to China. During his governorship, the state's first wind farm was built (Peterson, 2007), renewable energy zones (NCSL, 2009) were created, and Utah State University began working on algae as biofuel (USU.edu). However, Gary Herbert, Huntsman's successor, questions climate change science. Among other things, the resolution HJR 12 attacks the science and scientists behind climate change by claiming there is "a well organized and ongoing effort to manipulate global temperature data in order to produce a global warming outcome". A last-minute amendment removed the words "conspiracy", "gravy train" and "tricks" from the resolution, but the statements remaining were still 
inflammatory. The proposed Climate Change Joint Resolution can be found online at http://le.utah.gov/ 2010/bills/hbillint/hjr012.pdf More information concerning the process, amendments, committee reports, final draft form, and votes can also be found online at http://le.utah.gov/ 2010/htmdoc/hbillhtm/hjr012.htm

The Utah capitol has become hostile towards scientists when it comes to climate change. Representative Mike Noel claimed vehemently that climate change scientists all supported a conspiracy to limit population growth. Even fellow Republican Representative Phil Riesen was criticized when questioning Representative Noel's conspiracy theory. Noel said, "If you can't see a connection to that (population control), you're absolutely blind to what's going on. This is a conspiracy to limit population, not only in this country, but across the globe (SolveClimate Staff, Feb 10, 2010)”. This has led many scientists in Utah to believe some of the legislators have been manipulating the scientific evidence in order to support a political agenda. Representative Mike Noel, one of the main supporters of the HJR 12, has even gone so far as to call the president of Utah State University, a state-funded school, to complain about associate physics professor Robert Davies' testimony that did not support Noel's resolution. As the resolution neared its vote, the few scientists who dared object to the resolution where openly attacked by Representative Noel and other supporters.

Mark Clemens from the Utah Sierra Club believes that the State Legislature was not really ready for Governor Jon Huntsman's stance on climate issues and energy diversification. The Legislature is, and always has been, highly ideological and conservative. The resolution reflected, at least partially, the state of mind of the Utah Legislature and Governor Herbert, as well as the large influence of the fossil fuel and agricultural industry on the Legislature. According to the U.S. Energy Information Administration, close to 90 percent of Utah's electricity comes from coal. Sarah Wright, executive director of Utah Clean Energy and also a member of the BRAC board in 2007, believes that high rate of coal use is part of the reason cap-and trade is unpopular in Utah. "Many in Utah feel they will be paying double to reduce their carbon emission because they have to pay the allocations and change out our current electrical generation to non-carbon form. They feel it's a transfer of wealth from coal producing to states with hydro and nuclear (SolveClimate Staff, Feb 10, 2010)”.

Ironically, it was the CEO of Utah Farm Bureau Federation, Randy Parker (a member of the BRAC board in 2007 that had pushed some GHG reduction initiatives forward), who explained the resolution and its more inflammatory declarations item by item during the hearing. Parker went into economic issues, saying farmers would be forced out of business and the U.S. would be left relying on Mexico and China for food. The president of the Utah Mining Association and the executive director of the Utah Rural Electric Association also spoke in favor of the bill.

\section{The Blue Ribbon Committee on Climate Change}

In May of 2007 Governor Huntsman joined the Western Climate Initiative, a group of states, Canadian Provinces, and agencies within the region pushing toward the reduction of GHG emissions. Anticipating this move, Governor Huntsman organized in August of 2006 a group of stakeholders named the Blue Ribbon Advisory Council (BRAC) to suggest a GHG emissions reduction goal and strategies towards achieving it. Several of the other states that joined the Western Climate Initiative had also formed committees and held public participatory processes in order to come up with concrete plans to reach their GHG reduction goals. Oregon provides one of several examples of how these stakeholder processes have lead to changes in policy and also the adoption of laws to help move the clear goal of GHG reduction forward (ODOT, 2011).

At first glance, it seems that the BRAC was a critical process that involved a large amount of public participation and stakeholders. Many considered this a positive step forward towards true dialog in a state where Republican ideology has dominated. Figure 1 illustrates the decision-making process and the hierarchy of players involved. Twenty-four industry, government, community and environmental leaders were invited to participate as BRAC members. A Stakeholder Working Group (SWG) was also formed to assist in providing a preliminary evaluation of a broad list of policy options. Initially, nearly 200 options were organized under five major sectors headings: Agriculture/Forestry, Cross-Cutting Issues, Energy Supply, Residential/Commercial/Industrial, and Transportation/Land Use. 


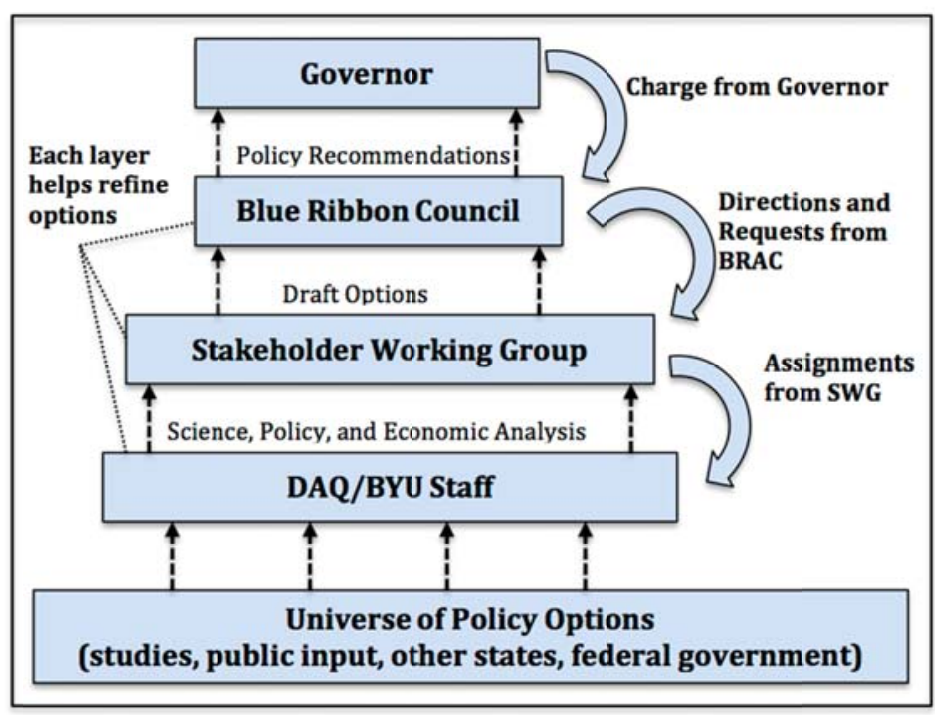

Figure 1. BRAC decision-making process

Brigham Young University research assistants and Department of Environmental Quality (DEQ) staff members gathered existing information on each option from "credible sources". SWG members and other subject experts who participated in the sector group discussions also provided information. Then, within the sector groups, each option was assigned a priority designation. The sector groups reported the results of their deliberations back to the entire SWG. Of the 88 options, only 14 sector designations were challenged. The SWG members voted on those cases that were in debate. The option papers and a summary table were then given to the BRAC who added three more options and then finalized priorities. By the end of the process the BRAC, SWG members, and sector group participants had invested an enormous amount of work in discussing and assessing the options. Their discussions were described as being "exhaustive, thorough, thoughtful, spirited, and congenial (BRAC, 2007, p. 5)". Participation in SWG groups was open to the public. A list of meeting times and locations was maintained on the DEQ website. Meetings of the BRAC and SWG were also open to the public. Information from the meetings and presentations were also posted on the website at http://www.deq.utah.gov/Issues/Climate_Change/index.htm. Questions and comments were accepted from the public throughout the process. Written public comments were posted at the end of each sector chapter in the final report. In the end, over 100 people participated in a total of 52 meetings.

\section{Analyzing Resolution HJR 12's Extremist Rhetoric}

Rhetoric specifically deals in the domain of the contingent or probable where multiple legitimate opinions or arguments are available. Aristotle's belief was that the "proper task" of rhetoric is to drive home the logic, truth, and evidence of an argument. Within this context extremist rhetoric's purpose seems to be the opposite. Gutmann states, "The opposite of a sound democratic argument is demagogy: manipulation and deception in order to divide and conquer the democratic populace. Extremist rhetoric is a common tactic of demagogy: it divides in order to conquer (Gutmann, 2007, p. 72)”. Extremist rhetoric has a very single-minded view on any given issue, and also passionately expresses "certainty about the supremacy of its perspective on the issue without submitting itself either to a reasonable test of truth or to a reasoned public debate (Gutmann, 2007, p. 71)". Unfortunately American political history provides an abundance of polarizing political rhetoric from both the left and right sides. Post 9/11, the Democratic Party compared George W. Bush and his administration to Hitler and the Nazis, while the Republican Party associated those who expressed opposition to the war and criticism of the Bush administration with those who committed treason. It is true that many citizens may initially be drawn to some forms of extremist rhetoric, but they find it increasingly troubling over time. Essentially, an abundance of extremist rhetoric endangers the public interest that democracy should serve.

The case study of HJR 12 exposes a few of the major ways in which extremist rhetoric divides, demeans, silences and deceives a large portion of its citizens. Topic control, nonresponse, and interpretive control play a critical role in public discourse and the maintenance of power. These three strategies are prevalent within the creation and passage of HJR 12, but I will be focusing mainly on the role that interpretive control plays in this case study. 


\subsection{Interpretive Control}

Interpretive control plays a large role in how extreme rhetoric works but may be hard to spot because it can be done silently by those who already have cultural domination. Lakoff elaborates, "Interpretive control is covert and potent, both psychologically and politically... It is not blatantly volatile, like interruption, or obviously inconsiderate, like nonresponse. Indeed it is so deeply rooted in our cultural expectations that it becomes hard to notice at all, like those optical illusions in which figure and background blend. Interpretation of the less powerful by the more powerful has been taken for granted in this and many other cultures for so long that it requires special awareness to notice it and novel responses to deal with it (Lakoff, 1995, p. 29)”. This type of interpretive control will be highlighted as I analyze several statements within the HJR 12 itself.

Before illustrating specific examples of interpretive control, I note that one of the main purposes of extremist rhetoric is to shut out the consideration of competing values, strategies, and worldviews. The purpose of HJR 12 is to gain back power that the Republican Party and other industries in Utah felt they had been gradually losing. This requires not only a shutting out or silencing of other voices - as noted in lines 13 through 17 of the resolution - but also a negative interpretation of the values and actions of those who disagree with them. The overall message seems to be that this resolution protects Utah citizen's liberty, security, and opportunity, while those who support misleading climate change science and the regulation of carbon dioxide are destroying them. But is it possible that the EPA's actions also could support liberty, security, and opportunity? The term "conspiracy" initially used within the resolution made that interpretation impossible.

\subsubsection{Labeling and Alienating Groups}

This labeling signaled the beginning of a war where parties focused on pointing fingers and interpreting each other's actions, instead of listening and creatively solving problems. Extremist rhetoric denigrates and degrades rather than respects those who beg to differ. Abortion-rights proponents become "baby killers". Anti-abortion advocates are "religious wing nuts (Gutmann, 2007)". And within HJR 12, over 98\% of scientists who have researched climate change become "climate alarmists". This is the most obvious way in which those with power exercise interpretive control over others. A more subtle way in which this labeling and alienation occurs can be seen in lines 38 to 41.

38 WHEREAS, emails and other communications between climate researchers around the

39 globe, referred to as "Climategate", indicate a well organized and ongoing effort to manipulate

40 and incorporate "tricks" related to global temperature data in order to produce a global

41 warming outcome;

The exploitation of word choices (lexical silences) such as "manipulate" and "tricks" plays a major role in the interpretation of the text. The function of these terms is not simply to justify the actions the resolution calls for, but to alienate and distance the common man from those scientists who support climate change theories. It even discounts the intelligence of the followers of those scientists. Callers to Rush Limbaugh's talk radio show are known as "Dittoheads" because they form an amen chorus to Limbaugh's extremist rhetoric. With this label, the unique qualities and opinions of those that listen to Limbaugh are discounted and thus silenced. The same type of alienation and generalizations are evident within this bill. Those who agree that climate change exists are "manipulators", or have been duped and are "alarmists" who run around like Chicken Little yelling, "The sky is falling". A group of Brigham Young University scientists were so disturbed by the wording of resolution HJR 12, that they wrote to the Legislature, highlighting several inaccuracies and urging them to reconsider. Near the conclusion of the letter, the scientists stated, "Even if all the political solutions proposed so far are flawed, this does not justify politicians in attacking the science that indicates there is almost certainly a serious problem (SolveClimate Staff, Feb 10, 2010)”.

The proponents of HJR 12 feel justified in pointing out uncertainty in climate change science and take advantage of the use of terms such as "almost certainly". Those who support the resolution would tend to emphasize the word "almost", just like they did the word "tricks" when referring to the "Climategate" spectacle, while ignoring the $90 \%$ or more certainty of the scientific evidence. Scientist's uses of these phrases are clear signs of their determination to depict as accurately as possible mathematical probabilities of events. Yet those within the political field have taken advantage of the doubt that naturally accompanies the analysis of complex issues, highlighting uncertainty and negatively labeling those scientists they disagree with while ignoring the uncertainty of science they choose to use in support of their own policy proposals. Haezle's (2011) research illustrates that the treatment of specialist advice on uncertain issues, particularly in the context of major policy issues, is largely determined by how well the advice fits with or contradicts the policy goals and values of the policy elite, not with the certainty of the scientific analysis itself. 


\subsubsection{Presuppositions}

Extremist rhetoric is also full of carefully chosen phrases laden with presuppositions. Presuppositions are inferential, making meanings available to viewers that are not made explicit (Jalbert, 1994). The introduction to the resolution on lines 14 through 17 provides an example of these types of presuppositions. The resolution calls for the EPA to halt specific policies until a "full and independent investigation" takes place. The logical presuppositions are: that a full and independent investigation has never taken place; that EPA scientists are alone in their findings about climate change within the scientific community; that somehow this particular type of investigation called for will steer clear of the pitfalls the EPA obviously encountered in all of their decades of research; and finally, that this investigation will be able to provide irrefutable evidence for or against the EPA's findings. Underlying this phrase is a much deeper supposition at play; the ability of science to answer in a definitive fashion how to move forward in complex issues. The rationalist policy approach popular in America today acknowledges uncertainty as something to be conquered rather than managed. If policy goes wrong it is common for policy makers to claim that their decisions were justified given the information they had. This implies that we can know the solution to uncertain problems through adjusting and improving our methods, resources and personnel used in the pursuit of knowledge. This allows those who support the resolution to delay productive dialog by insisting that action must wait for irrefutable "truth" to appear.

Presuppositions also occur due to proximity of one statement to another. It is natural to link a previous statement to the next - to orient a statement based on what has already been presented. If your friend tells you she broke her arm at work and she is quitting, you assume she is quitting, because she broke her arm. In reality, a multitude of reasons could exist as to why she is quitting. We constantly deal with presuppositions within our speech and texts. However, problems arise when ideological messages that should otherwise be proven are communicated through presupposition (Bekalu, 2006). Consider what may be presupposed in lines 59 to 64 due to the proximity of the first statement to the second.

59 WHEREAS, the United States Department of Agriculture estimates that current

60 legislation providing agriculture offsets and carbon credits to reduce $\mathrm{CO} 2$ emissions would

61 result in tree planting on 59 million acres of crop and pasture land, damaging America's food

62 security and rural communities;

63 WHEREAS, according to the World Health Organization, 1.6 billion people do not

64 have adequate food and clean water; and

In this case, the bill claims that proposed cap and trade policies will lead to a very large decrease in crop and pasture land in America. The next phrase mentions the current lack of adequate food and clean water for 1.6 billion people throughout the world. Many presuppositions are needed to link these two thoughts together. First, there is the supposition that Americans will not find any other option besides offsetting carbon credit through planting trees and that there will be no other land available for planting trees except crop and pasture land. The image of the United States filled with trees from end to end comes immediately to mind. Second, when connecting this image of a country overrun with trees and no land for crops with the new thought of billions of people with not enough food and water, the assumption is that there is lack of availability of food and water because of a growing lack of crop and pasture land. What is never mentioned is that the current 1.6 billion people who do not have adequate food and clean water however is mainly due to a lack of accessibility to food and water, not due to the amount that is produced. Third, these thoughts intermingle, leading to assumed images of what America will turn into: a land full of trees, no food, and starving people. The presuppositions due to the proximity of these phrases are powerful and encourage emotional responses instead of clear cause and effect thinking.

Questionable cause and effect thinking is commonplace within legislative processes at local, state, and national levels but becomes much more obvious within extremist rhetoric. It is psychologically comfortable and politically attractive to convince ourselves that we know what we really do not know, and then construct strategies that are only sound if a certain preferred image of the outside world proves to be true. This approach however does not lead to successful policy. It is far better to choose a course of action that minimizes the risk of harm done and maximizes the chance of benefits no matter which worldview turns out to most adequately address our current challenges. An interesting example of this type of approach occurred in the Netherlands First Sustainability Outlook in 2004. Four different archetypal worldviews on sustainable development were used to create four different scenarios for policy analysis. The Netherlands Environmental Assessment Agency was able to identify policy options that would be robust under several worldviews (Vries \& Petersen, 2009). It is possible for validity of action to be maintained while allowing the consideration of a range of futures. In fact, approaches that tend to include values, worldviews, and interests in a thoughtful and integrative way can create much more 
legitimacy in the long run. Extremist rhetoric ignores this principle, providing a foundation where one worldview must dominate and all others discounted and silenced.

\subsubsection{False Arguments}

Lines 29 through 33 of the resolution provide yet another way in which the careful choice of words used in extremist rhetoric may disorient and manipulate the general public.

29 WHEREAS, global temperatures have been level and declining in some areas over the

30 past 12 years;

31 WHEREAS, the "hockey stick" global warming assertion has been discredited and

32 climate alarmists' carbon dioxide-related global warming hypothesis is unable to account for

33 the current downturn in global temperatures;

The term "global warming" sprinkled throughout the resolution provides a subtle yet powerful interpretation of scientists' message concerning carbon dioxide emissions and how it affects the climate on earth. This term emphasizes a false idea that scientists are claiming there is a constant increase in temperatures every year in every location throughout the globe, that, for instance, this year the average temperature will be 89 degrees in Utah and next year it will be 90 degrees. The purposeful avoidance of the term "climate change" and the adoption of the old term "global warming" silences the complexity of the theories associated with the scientists in question. Thomas Huckin refers to this type of word choice exploitation as a "lexical silence" (Huckin, 2010). This false idea of climate change is given further credence by the statement in line 29 that "global temperatures have been level and declining in some areas". Placing these statements within the resolution implies that this downturn in temperatures is relevant in supporting the resolution while disproving scientists opposite claim that every year throughout the globe temperatures were constantly increasing.

This is a perfect illustration of how those who resort to extremist rhetoric tend to falsely reveal a value, belief, or claim of the opposing side and then victoriously refute the false claim with their own evidence. This type of rhetoric turns into a fake dialog-a pretended public debate that is solely authored by one party, but appears to be acted out by both parties. At times these fake dialogs can be pushed to the forefront of debate and not dropped, thus forcing the other side to respond. This shuts out time and space for real dialog, silencing issues that the public cares about. It leaves the public with a sense that politics has become entertainment, a series of dramatized confrontational accusations. When this type of false dialog prevails, citizens wiling to grapple with complex issues in a mature manner are turned off by the forums available. Inevitably the ability to make wise decisions for the public good is seriously hampered.

\subsubsection{Blocking Constructive Examination and Reasoned Public Debate}

One main purpose of extremist rhetoric is to reclaim or reveal the dominance of one group over another. Gutmann elaborates on one of the main pitfalls associated with those who seek public power: "Even granting that some extremists are right, we still must recognize that the vast majority of people who seek public power and influence are all too prone to believe without warrant-yet with subjective certainty-that they have the absolute right on their side (Gutmann, 2007, p. 75)". Nietzche said, "Power makes stupid (Nietzche, 1967, p. $60)$ ". In this case, dominating power and the resulting extremist rhetoric destroy the possibility of reasoned public debate and constructive examination - examination that could lead to better policies.

The word "conspiracy" plays a pivotal role in destroying the possibility of scientific objectivity, understanding the real complexity of climate change science, and articulating what is known and what is not known. All scientists who support the idea of climate change, and their last 30 years of research, were invalidated, ignored, and annihilated. One would then assume that any scientific evidence that the supporters of the resolution produced would be of the highest caliber-that all scientific research would be subject to the same sort of scrutiny. Extremist rhetoric ignores this principle of constructive examination. One such scientific argument the resolution highlights deals with one article published in 2009 about Chlorofluorocarbons.

34 WHEREAS, there is a statistically more direct correlation between twentieth century

35 temperature rise and Chlorofluorocarbons (CFCs) in the atmosphere than $\mathrm{CO}_{2}$;

36 WHEREAS, outlawed and largely phased out by 1978, in the year 2000 CFC's began to

37 decline at approximately the same time as global temperatures began to decline;

The proponents of the resolution do not mention that the scientific community has had little time to respond to this one article that contradicts thousands of others. Even some scientists who do not support a cap and trade policy find this use of scientific evidence in the resolution deceptive, if not unethical. They wrote, "So it appears that the authors of H.J.R. 12 are willing to brush off thousands of scientific publications over several decades 
because of a few comments taken out of context from some stolen e-mails. But if a single paper is published that contradicts the consensus position on the causes of recent climate change, they immediately put it forward as proof that the consensus is wrong. This is as illogical as it is irresponsible (Brickmore et al., 2010, p. 2)”.

It is evident that being logical and rational was not a priority of those supporting the resolution. Several scientists offered to assist in creating much more sound arguments and a much more scientifically credible resolution, but all offers were ignored. Professor Phil Emmi from the University of Utah explained why such an offer could be rejected. "These politicians need not be reasonable, and they know they can get away with such nonsense. But don't think for a moment that climate - denying politicians are dumb. On the contrary, they understand well their political support base. They enjoy the backing of industries that stand to lose profits if responding to global warming means an increase in production costs. These politicians play expertly upon the fears of those who would truly be hurt by change. And they encourage those who heap scorn when confronted. Their political power lies in their ability to capitalize on the frailties of the human spirit. They take such strength from human weakness that they can thumb their noses at reason itself (Emmi, February 9th, 2010)”. Bent Flyvberg has observed that, "Power has a clear tendency to dominate rationality in the dynamic and overlapping relationship between the two (Flyvberg, 1998, p. 234)”. In other words, those supporting HJR 12 new from experience that power wins over rationality.

\subsection{Case Findings From HJR 12}

When looking back at the history of the climate change issue in Utah, it is apparent that those who had been accustomed to the power they had previously possessed within the political system were not comfortable with any proposals for a cap and trade system. Predictably, these power players became resentful and used the traditional tool of extremist rhetoric at hand to reassert their position and silence helpful dialog. The interpretive control used by those supporting HJR 12 allowed an atmosphere where reasoned public debate and constructive examination was not possible. The process was riddled with the labeling and alienation of groups, a host of ideological messages that should have been proven but were presupposed, and fake dialogs that used up valuable time for real and productive discussion. Not only does extremist rhetoric divide, demean, and silence productive dialog at a state level, but it also had the potential of effecting Utah's legitimacy at the federal level. Dr. Gary Brickmore, a fellow Republican, said, “The main message it (HJR 12) will send is: 'Don't bother considering our concerns, because we are not willing to participate in an authentic discussion about this topic (Youtube.com, February 14, 2010).'”

Underlying this legislative process is a reliance on the rational model and a belief that people have the potential to control and impose order on the natural and political environment. The legitimization of democratic governments comes about through the just balancing and arbitration of the power of the State with the liberty of the individual. The general public must broadly see the actions of the State as non-arbitrary and rational applications of state power focused on national interest in order for legitimacy to continue. The idealization of the rational model brings about assumptions concerning what we do know and can know. Data is assumed to be true and pure, separate from politics, worldviews, and interests. Booher and Innes (2010) explain that popular rational ideas such as optimization depend on assumptions of certainty and static contexts that do not apply to most policy problems. Problems such as climate change are "wicked" ones with multiple and conflicting goals. Applying such strategies can lead to premature closure on solutions and the institutionalization of arbitrary rules and procedures. Embracing the idea that uncertainty is inevitable may initially challenge the assumptions that support the very legitimacy of the legislative process itself, but it is necessary in order to handle the complex issue grappled with today.

Heazle (2010) points out that policy makers habitually portray the policies they make as flowing directly from facts. Strong political incentives underlie such portrayals. The policy maker looks good in that he is perceived to be acting on facts rather than on beliefs, hunches, or wishes. He looks informed rather than ignorant. He gains better support for his policy, which is depicted as a product of reality and necessity rather than ideology. Knowledge is clearly a part of the story, but not all of it. When uncertainties and political stakes are high it is the interpretation of knowledge that plays the lead in explaining why policy makers in their justification of one policy over another often treat expert advice so inconsistently. Flyvberg explains how this inconsistent employment of science and knowledge produces a source of legitimacy that initially masks the illegitimate (irrational) use of pure power in democratic societies. "In open confrontation, actions are dictated by what works most effectively to defeat the adversary in the specific situation. In such confrontations, use of naked power tends to be more effective than any appeal to objectivity, facts, knowledge, or rationality, even though feigned versions of the latter, that is, rationalizations, may be used to legitimize naked power (Flyvberg, 1998, p. 232)”. 


\section{Analyzing the Silence Fostered Within the Blue Ribbon Committee for Climate Change}

Ironically, several of the key supporters of HJR 12 were also a part of the Blue Ribbon Committee for Climate Change a few years earlier. While in this committee, they had approved a report for Governor Huntsman that supported the general science of climate change, and had agreed on several strategies to reduce GHG emissions (BRAC, 2007). A careful examination of the news release in Figure 2 reveals the political tightrope Governor Huntsman was traversing when joining the Western Climate Initiative and bringing up the issue of climate change. In fact, one of the biggest indicators of this tightrope is the lack of the phrase "climate change" within this press release. At the time, Utah's public commitment to reduce GHG emissions was still young. The governor's office was just beginning to realize its role in environmental consciousness. Huntsman, a conservative Republican, wished to provide a middle ground where this very controversial subject could be discussed constructively. Above all, what he didn't want was the extremist rhetoric that ended up taking place several years later with HJR 12.

\section{NEWS RELEASE}

August 22, 2007

Contact: Dianne Nielson

Energy Adviser to Governor Huntsman

(801) 538-8802

Rick Sprott

Executive Director DEQ

(801) 536-4404

Utah to Set its Own Greenhouse Gas Reduction Goal

Salt Lake City - Governor Jon Huntsman announced he will work with Utah industry and other stakeholders to develop State goals to reduce greenhouse gas (GHG) emissions as part of a regional initiative to reduce emissions by 15 percent by 2020 released today.

In May, the Governor joined with the Western Climate Initiative (WCI), six states and two Canadian provinces, committed to reducing GHG emissions in the West, including establishing a regional GHG reduction goal by the end of August 2007. Presently, Arizona, California, New Mexico, Oregon, Washington and the provinces of British Columbia and Manitoba, have individual state/provincialGHG goals.

The regional goal is an aggregation of goals from all eight WCI members, but it does not replace the members' individual goals.

As part of joining the WCI, Huntsman committed the State to developing a GHG reduction goal by June of 2008. He intends to use a stakeholder-based process to establish targets for greenhouse gas reductions based on economic factors and consideration of all sectors of the economy that generate greenhouse gas emissions. The goal also will reflect the Blue Ribbon Advisory Council's pending recommendations to the Governor.

In Utah, electricity generation and vehicles are the two largest sector emitters of GHG. Coal-fired generation provides about 85 percent of Utah's electricity. Technologies can be implemented to capture and sequester carbon dioxide from coal-fired power plants. Emissions of GHG from vehicles can be reduced through changes to lower carbon fuels and increased miles per gallon ratings on vehicles.

"Coal-fired generation will remain an important part of our energy mix," Huntsman said. "Utah’s goal will encourage economic development through new and innovative technologies while improving energy security, broadening and enhancing our renewable energy sector of our economy and improving the air quality in our State.”

Figure 2. News release 
Huntsman's tactic for discouraging extremist activity came through the use of a highly bureaucratic and stable process. Rational considerations tend to have the most influence within a framework of stable power relations. Yet Flyvberg (1998) also points out that "stable" power relations are not necessarily "equally balanced" power relations. Stability does not guarantee that all involved parties act on equal terms and justice is achieved. Stable relations of dominance may lead to distortions in the production and use of rational or quasi-rational arguments (rationalization). Huntsman's strategy may have eliminated much of the tendency to vilify those on the other side of the argument, but it also created an atmosphere where profound transformation was inhibited. Bureaucracy, and especially rationalization, constrains emotionality, privileges instrumental processes and those already holding power, and excludes alternative modes of organizational experience. It seems that this bureaucratic process of the BRAC not only created a constrained space for problem solving, but it also primarily placed the power to eradicate the problem in the hands of those who gained the most by perpetrating it and gained the least by changing their current views on power production.

\subsection{Constraining the Future Through Topic and Interpretive Control}

Social change depends to a large extent on visions of the future that motivate and compel action today. However this type of change is often impeded by the prominence of images or visions that maintain and extend the status quo. HJR 12 provides a very vivid example of the use of the future as an ideologically potent site through which partisans attempt to wield power over others. The resolution's image of a world with carbon dioxide emission constraints is a bleak one-where America's food security and rural communities are threatened, and where billions of human beings are "locked into long-term poverty". The authors of HJR 12 would have the public believe that the first step in preventing this horrible tragedy is, of course, to support the resolution. These tactics that are used by both Democrats and Republicans alike may seem manipulative at times. But political and governmental action primarily relies on the assumption that they have a reasonable understanding of what the future may hold. It is through these grand visions of the future that valid reasoning appears for governments to take action.

In the BRAC process, the constraints placed upon future visions are much more difficult to pinpoint, but still inhibit radical new understanding that may lead to permanent change. Figure 2 is a news release that subtly reveals several of the assumptions and limitations that were in place even before the process began. The use of topic control and interpretive control permeates it. It is true that a short news release cannot articulate all aspects of a complicated issue. However it is evident that this particular news release contains a large amount of repetition on certain themes and topics, while repeatedly silencing others. It is very common for writers and speakers to frame public issues by mentioning certain relevant topics or themes while ignoring others. In this case, these themes intended by Huntsman to appease those most threatened by climate change initiatives also end up constraining the possible outcome of the process before it even officially starts. And although this press release was made available well into the process, these focuses and constraints were apparent in the design of the process itself as well as in the instructions and communication from the governor during the creation of the BRAC.

\subsubsection{Emphasis on Utah's Independence and Voluntary Choice to Participate}

Huntsman's first theme provides the Republican Party with a new way of framing the climate change debate. This initially seems like a wise strategy, considering Utah lawmakers' large aversion to complying with laws and rules created by other parties. The title "Utah to Set its Own Greenhouse Gas Reduction Goal” provides a positive spin for those in the state that pride themselves on being fiercely independent. The overabundance of the term "GHG emissions" and the complete lack of the anticipated term "climate change" throughout the news release points to the governor's wish to re-define or reframe the subject. In essence, the governor is asking stakeholders to move forward with pride in Utah's independence and natural progression.

Information about the Western Climate Initiative focuses on those participants who already have agreed on GHG emission reduction goals. The point was that everyone else sees the need for this; therefore creating a GHG reduction goal must be a reasonable thing to do. The press release highlights yet again the idea that Utah decides independently what they will do, that it is purely voluntary. The last paragraph closes by supporting the idea that Utah is voluntarily participating in this initiative, because, ultimately, it makes good economic sense and that this is a natural progressive path that Utah is already on. "Utah's goal will encourage economic development through new and innovative technologies while improving energy security, broadening and enhancing our renewable energy sector of our economy and improving the air quality in our State”. This confirms the ideas that there is no reason to panic, citizens' and businesses' daily interactions will continue as usual, and the natural progression within the energy production industry will have a positive effect on the economy. The tradeoff of this approach 
is that this message silences much of the reasoning behind the GHG goal, and thus makes inconvenient change that might be necessary in the future much harder to adopt.

\subsubsection{Limiting the Scope of Discussion and Possible Solutions}

One of the most critical questions in a public relations process is: What is the real problem or issue that we are dealing with? If this question is not answered with the correct scale, complexity, or visionary possibility in mind, the public process and possible powerful results can be seriously hampered. Huntsman indirectly answers this question by his choice of contact personnel, the energy advisor to the governor. This choice subtly infers that the reduction of GHG is an energy issue, not an ethical or cultural issue. Climate change is something that can only be handled by those who currently produce the energy and emit the GHG and the governmental agencies that regulate those producers and consumers.

Huntsman continues to define the answer to this question by establishing targets for greenhouse gas reduction primarily based on economic factors. He also insists that all sectors of the economy that generate greenhouse gas emissions should be considered in the analysis but then focuses on the two largest sector emitters of GHG, coal-fired generators and vehicles. He does not even mention the consumers. It is also apparent that Huntsman seems to already have formulated a large portion of the answer to this GHG emission problem: carbon dioxide sequestering and lower carbon fuels with cars that have greater fuel efficiencies. His vision of the future revolves around technical fixes that guarantee "Coal-fired generation will remain an important part of our energy mix". In effect, the vision of the future is one where culture, lifestyle, habits, and power sources stay more or less the same as before with only slight adjustments being made to expand new economic possibilities while ensuring energy security.

Governor Huntsman instructed the stakeholders to keep in mind current economic and power consumption realities of Utah when deciding on a GHG reduction goal. The limitations of his focus and the accompanying future vision Huntsman offers may not be completely apparent until a comparison is made to another possible answer to the question "What is the real problem or issue that we are dealing with?" One plausible response to this question might be that the real issue here is climate change and a recognition that our current GHG production is a direct result of our current way of living - the way our cities are designed, the constantly increasing demand for energy and resources per capita, the dramatic increase of people on the earth, the way we build and design structures, the way in which we obtain and preserve our food, how we move ourselves and other items around on this planet, and how we communicate in this world. This type of framing brings to light those ideas that Governor Huntsman's frame of reference ignores.

Because current GHG emissions are entwined in our very way of living every day in Utah, the question might be, "How are we going to plan for a future where our planet's environment may be very different from the present and where our primary sources of current energy use will become more and more difficult to access?” This question is visionary in nature and is much more powerful than Huntsman's question which limits possibilities based on the status quo. It provides the opportunity for a more thorough, multifaceted, and ultimately effective public process, because, suddenly, more stakeholders appear (namely the public) due to the incredible value judgments associated with the question. But this possibility is immediately silenced before the process even begins. In this case, power (Huntsman and the Republican Party) demanded silence for any movement forward in climate change discussions.

Dr. Hans G. Ehrbar, one of the participants of the Renewable Energy Initiative Group, expressed his frustration in the limited scope of the inquiry in a letter to the Blue Ribbon Council. He wrote, "The question is not whether renewable energy is cheaper than fossil energy; the question is how we can use the available economic resources most productively to make this switch, and how we can remove any regulatory, legal, and organizational obstacles which are the leftovers from a different time period. This is a common goal transcending the economic interests of which the participants are the representatives (REI, 2007, p. 2)”.

\subsubsection{Establishing the Most Important Stakeholders and Their Dominant Role in the Process}

The only specific stakeholder mentioned at the beginning of the press release is "Utah industry". Utah industries are the ones Huntsman wishes to cater to in this press release and also during the process. Although many praised the openness of the process and access the public had, in reality, the process became more of a playing field for industries and governments, not the general public. The process chart of public participation located in Figure 1 illustrates the top-down approach and the stakeholders with a voice in the process. Many of the 24 BRAC members appointed by the governor represented the main sources of GHG emissions in the state. These people should be involved in this process, but they held an inordinate amount of the power. Both the Climate Change Work Group (CCWG) and the research group worked under the express direction of the BRAC. If the 
research group or CCWG had findings or information that the BRAC disagreed with, it was not allowed in the report.

Ironically there are times when a blue ribbon committee created to combat a problem may, in fact, support the power that created the problem in the first place. In this case, the design of the process itself supported the power structure that had created the GHG emission problem. Since the report from the committee was just a recommendation that Governor Huntsman would take into account, and since there was not broad public involvement during the process, major industries knew that they were not truly bound to the results. If they felt threatened in the future by proposals to the Legislature, then they could backtrack and dig in their heels just like they ended up doing with HJR 12. But they also could appear to be cooperative and responsive to the needs of the community while in the BRAC and while Huntsman was in office. Industry representatives had very little to lose in this case, and they had a high amount of influence during the process.

Of course, the ultimate decision maker was Huntsman. There was to be a GHG reduction goal. That was definitive. The committee was to provide a recommendation as to the GHG goal for the state. This limited the Republicans from flat out denying or refusing to discuss the reality of GHG emissions and climate change. But it also was clear that a Republican governor was not going to adopt a policy that would be considered extreme. In essence, Huntsman wanted his committee to identify the low-hanging fruit - those approaches to GHG reduction that would not cause too much resistance from Utah industries. Therefore, this process did insist on some sort of movement forward, yet was not open to dramatic and complex solutions to meet the challenges climate change could bring to Utah.

\subsubsection{Limiting the Possible Outcomes Through a Short Process}

Although the BRAC was organized by Governor Huntsman on August 25, 2006, the first meeting did not take place until January 2, 2007. Final recommendations from the BRAC were scheduled to be submitted in October of 2007, leaving almost ten months for the process. The quick timeframe Governor Huntsman gave for completion of the task only allowed the committee to identify a wide range of options for GHG emission reduction, organize and consolidate the options into a manageable list, provide a brief assessment, and then make an initial effort to rank and prioritize them. Within the limited time frame, the BRAC, SWG members, and sector group participants invested an enormous amount of work in discussing and assessing these options. Even more significantly, the BRAC and SWG both supported an "economy - wide" approach with a variety of options being considered. This was a decisive improvement in that during some of these meetings real thoughtful and congenial discussion took place.

However the short time frame for the process also eliminated the potential for dramatic progress and real public involvement that other stakeholder processes had experienced. Original research or state-specific economic evaluation of each option was not possible. The reports did include information on the cost of $\mathrm{CO}_{2}$ avoidance or reduction that was obtained from analyses used by other Western states. That information was usually cryptic and rarely included detailed explanation. Therefore, voting on the options that would be of most benefit and the associated costs of implementation were primarily based upon previous beliefs of committee members. The BRAC encouraged the governor to conduct "Utah-specific economic cost benefit analyses" for those policies the committee supported. The BRAC also acknowledged, "that while there may be costs and benefits associated with the policy recommendations in this report, any economic analyses conducted must also take into account the potential costs associated with inaction. Both may need to be considered (BRAC, 2007, p. 7)”. Of course there was no way to analyze the cost of inaction within the short time frame of this process. Nor was there any concerted effort after the report was turned in for the public to become heavily involved with further progress.

Governor Huntsman also organized a Renewable Energy Initiative (REI) Focus Group in late June 2007. This group was to be a "technical" group that would develop "detailed public policy actions" to be used by leaders to increase the development of "cost effective" renewable electric energy resources. The first meeting took place on July 9, 2007, and two to four hour meetings took place almost every weekend up to October 19th, 2007. There was no possible way for the REI focus group to conduct the analysis necessary to produce a report that could have really been considered technical in nature. Due to time constraints, they used Oregon as a strawman policy. Instead of providing a comprehensive survey from which the group could choose the best elements, there was an overview of various stakeholder positions on elements of a single plan adopted in Oregon. The lack of technical analysis was objectionable to many in the group, but inevitable.

It is apparent that the report from the BRAC committee was turned in less than halfway through the decision process. What could have followed was a large amount of research specific to the state of Utah. BRAC could have agreed upon the types of research and data that would be considered relevant in a public participation 
process. The public participation process could have been highly informative, with policy options and consequences specifically relevant to Utah discussed. The results of the public participation process could then be used to push forward specific policies or could lead to initiatives on the next voting ballot. Statewide support and political will could have been achieved through in-depth public dialog, interactive surveys and workshops, and scenario planning. This type of extended process was used in other states and territories when deciding upon their GHG emission reduction goals (ODOT, 2011). Because of the extended process, movement forward was not entirely dependent on who the governor would be two or ten years down the road. In essence, those in authority had voluntarily given a small portion of their power back to the people who had appointed them, but in the end gained more power and legitimacy for future endeavors due to constructive outcomes.

\subsection{Case Findings From the BRAC Process}

While Huntsman was able to discourage extremist activity, he created an atmosphere where profound transformation was inhibited. Huntsman's vision of the future was very limited in scope, thus appeasing those most threatened by climate change initiatives. This constraint on the topic, and his interpretive control also limited possible outcomes before the process even started. Huntsman's emphasis on Utah's independence and voluntary choice to participate is evident throughout the process. However this tends to silence much of the reasoning behind the GHG goal to the public, and thus makes uncomfortable adjustments that may be necessary in the future much harder to adopt. The scope of the process was also limited by Governor Huntsman's instruction to the stakeholders to keep in mind current economic and power consumption realities of Utah while deciding on a GHG reduction goal. Because of this emphasis the question at hand became whether or not renewable energy was cheaper than fossil fuels, which was altogether beside the point.

However, one of the greatest influences in topic and interpretive control was the design of the process itself. Although many praised its openness, the process itself supported the power structure that created the problem in the first place and ultimately became a playing field for industries and governments. Major industries as well as those within the Republican Party understood that the report was a recommendation that Governor Huntsman would take into account. They were truly not bound by the results because the process was cut short and public involvement was limited. Industry representatives and the Republican Party had very little to lose in this case, and had a high amount of influence during the process. Huntsman chose a process that guaranteed that power would generally be maintained by the governor and the Republican Party. This led to the possibility of creating HJR 12 a few years down the road, and thus encouraged extremist rhetoric. The short process also stymied the power of rationality because valid scientific data specific to Utah was seldom available. Even though discussion was much more civil, recommendations to the governor were primarily based upon previous beliefs instead of any sort of groundbreaking definitive research presented. Therefore the outward impression that a truly rational process had taken place was deceptive.

\section{Discussion}

These two cases illustrate dramatic differences in how silence may be encouraged. HJR 12 illustrated how extremist rhetoric and the accompanying interpretive control alienated those who disagreed, erased decades of scientific research, and deceived the public by concealing climate change science's true arguments while providing fake arguments they could refute. This strategy has historically been used by both parties at the state and national level as they jokey for power. The BRAC process illustrated how bureaucracy and rationalization may constrain possible future visions and actions, reinforce current power structures, and encourage extreme rhetoric further down the road. Topic and interpretive control permeated the process in a subtler manner and limited the possible outcome even before it started. The timeline constraints also discouraged a deeper understanding of climate change and specific solutions for Utah and silenced statewide dialog that could have more dramatically and consistently moved GHG emission reduction forward. Many Blue Ribbon Committees on a host of subject matter throughout the nation have experienced similar limitations and pitfalls within their processes.

Even with major difference in these cases, both political forums chose to silence the general public, thus stymying the opportunity for true deliberation leading to better decisions and policies. Some believe that the public is not capable of dealing with these complex issues. Here we face a dilemma: How is the public to gain the necessary experience needed to develop passionate as well as reasonable rhetoric when the opportunities for such engagement are rare? Opportunities to engage in thoughtful deliberation concerning complex issues are seldom provided at a city, regional, state, or national level in the United States. Professor James Fiskin, at Stanford University, seeks to increase engagement through a process known as deliberative polling, where citizen's viewpoints about complex policy issues are polled before and after a carefully balanced deliberative and 
informative process (Youtube.com, May 4, 2010). After these processes take place the results are made available in a transparent way so that policy-makers have cover to propose legislation based primarily upon the informed wishes of their constituents instead of their own ideological framework. The average citizen's voice can then be heard again instead of being drowned out by those with extreme political views. As we have seen from our two cases, a community that rarely experiences the power of cooperative creative discovery and problem solving has a natural tendency to fall into the power play traps encouraged by different political forums. In the short term those with the power are the winners, yet in the long run we all lose.

This analysis uncovers several underling assumptions about rationality, power, and scientific knowledge that limit the ability to grapple with complex problems in meaningful ways. The idealization of rationality leads to impasses that create irrational extremist rhetoric and impotent committee processes. At best these approaches tinker at the edge of critical issues such as climate change and green energy production, and at its worst results in bad policy decisions. In both political forums uncertainty was interpreted by those who maintained power as proof of the assurance and reasonableness of their own views and policy wishes while silencing those who disagreed. In this sense rationality and democracy played a much smaller role in policy outcomes then many would assume. These examples illustrate that instead of thinking of democracy and rationality as a means of dissolving power, we can see them as practical attempts at regulating power and domination. Flyvberg explains that, "We may want the democratic element in government to grow greater, but it still is only an element. Efforts at implementing democracy are a constant, never-ending task existing in conflict with traditions of class, tribe, and privilege... In this sense, modernity and democracy must be seen as part of power, not the end points of power (Flyvberg, 1998, p 232)".

These findings stress the necessity of new models and processes that respect diverse views and interests, and provide ways to move forward while decreasing irresponsible oversimplifications of the challenges ahead. This paper highlights some of the pitfalls associated with the idealization of the rational model. However, completely rejecting the objective realm (scientific knowledge and evaluation) while idealizing a purely subjective approach also creates its own impasses. Scientific knowledge is critical in the education of ecosystems, resources, and technical development. And encouraging personal and societal change requires a deeper understanding of values, worldviews, and interests. Both approaches are necessary. My call is to resolve the tensions between objective (scientific deliberation and data collection) and subjective (values, worldviews, cognitive maps) notions of sustainability through a more integrative approach that: (1) explicitly recognizes that uncertainty exists when grappling with complex problems, and that scientific research can only go so far in answering these questions; (2) openly engages with value, worldview and interest disputes in a respectful yet critical way and; (3) expands visions of possible futures based upon a variety of conceptual and empirical relationships of importance. Three models come to mind that may assist our understanding of how science and rational thought may contribute in political processes in a more integrated and productive manner: Judith E. Innes and David E. Booher's principles of "collaborative rationality" (2010); de Vries and Petersen's assessment methodology mentioned in 4.1.2 (2009); and "post-normal science" principles articulated by Funtowicz and Ravetz (2003). Recent stakeholder processes throughout the country are starting to adopt some of these new approaches and principles. But current impasses on complex issues such as the national budget and gun control illustrate that it is still yet to be seen if American legislative forums will be able to fully embrace some of the key principles underlying these more integral approaches.

\section{References}

BRAC. (2007). Executive Summary. Retrieved March 28th, 2013, from http://www.deq.utah.gov/DocLibrary/docs/2011/brac/Final_Report/Sec-1-BRAC_EXECUTIVE_SUMMA RY.pdf

Bekalu, M. A. (2006). Presupposition in news discourse. Discourse \& Society, 17, 147-172. http://dx.doi.org/10.1177/0957926506060248

Bickmore, B. R., Rupper, S. B., Nelson, S. T., Radebaugh, J., Christiansen, E. H., Bekker, M. F., ... Dorais, M. J. (2010). To the members of the utah state legislature. Retrieved March 28th, 2013, from http://extras.mnginteractive.com/live/media/site297/2010/0204/20100204_024750_Legislature2.pdf

de Vries, B. J. M., \& Peterson, A. C. (2009). Conceptualizing sustainable development; An assessment methodology connecting values, knowledge, worldviews and scenarios. Ecological Economics, 68, http://dx.doi.org/10.1016/j.ecolecon.2008.11.015

Emmi, P. (2010). [E1343] An essay inspired by HJR 12 climate change joint resolution. Retrieved March 29th, 2013, from http://greenhouse.economics.utah.edu/pipermail/energy/2010-February/001343.html 
Faucault, M. (1982). Is it really important to think? An interview. Philosophical and Social Criticism, 9, 29-40. (Keenan, Trans.).

Flyvberg, B. (1998). Rationality and power: Democracy in practice. Chicago, ILL: The University of Chicago Press.

Funtowicz, S., \& Ravetz, J. (2003). Post-normal science. Internet encyclopedia of ecological economics. Retrieved March 26th, 2013, from http://korny10.bke.hu/angol/ravetz2003.pdf

Gutmann, A. (2007). The lure \& dangers of extremist rhetoric. Daedalus, 136(4), 70-78. http://dx.doi.org/10.1162/daed.2007.136.4.70

Heazle, M. (2010). Uncertainty in policy making: Values and evidence in complex decisions. Washington, D.C.: Earthscan.

Huckin, T. (2010). On textual silences, large and small. In C. Bazerman et al. (Eds.), Traditions of writing research. London: Routledge.

Innes, J. E., \& Booher, D. E. (2010). Planning with complexity: An introduction to collaborative rationality for public policy. New York, NY: Ruetledge.

Lakoff, R. T. (1995). Cries and whispers: The shattering of the silence. In K. Hall, \& M. Bucholtz (Eds.), Gender articulated: Language and the socially constructed self (pp. 25-50). New York, NY: Routledge.

McMorris-Santoro, E. (2011). Every single GOPer on house energy committee won’t say climate change is real. TPMDC. Retrieved March 26th, 2013, from http://tpmdc.talkingpointsmemo.com/2011/03/every-single-goper-on-house-energy-cmte-wont-say-climatechange-is-real.php

National Conference of State Legislatures. (2009). States tackle energy in 2009 volume 5: Renewable energy zone legislation. $\quad$ Retrieved March 30th, 2013, from http://www.ncsl.org/issues-research/energyhome/volume-five- renewable-energy-zone-legislation.aspx

Nietzche, F. (1967). Beyond Good and Evil. New York, NY: Vintage Books.

ODOT. (2011). Greenhouse gas initiatives in oregon: Technical overview. Last retrieved March 26th, 2013 from http://www.oregon.gov/ODOT/TD/OSTI/docs/media/technical.pdf

Peterson, J. (2007). Preliminary work begins on utah’s first wind farm. Daily Herald. Retrieved March 31st, 2007, from http://www.heraldextra.com/news/local/preliminary-work-begins-on-utah-s-first-wind-farm/article_444d58 35-ceef-5b2a-b6f9-8a6215be9e2f.html

REI. (2007). Focus group public comments. Retrieved March 28th, 2013, from http://www.deq.utah.gov/DocLibrary/docs/2011/brac/Final_Report/Sec-E-2-REI_PUBLIC_COMMENTS.p $\mathrm{df}$

SolveClimate Staff. (2010). Utah house passes resolution implying climate change conspiracy. Retrieved March 28th, 2013, from http://insideclimatenews.org/blog/20100210/utah-house-passes-resolution-implying-climate-change-conspir acy

Utah State University. (2013). Research and innovation. Retrieved March 31st, 2013, from http://bioenergy.usu.edu/htm/research

Youtube.com. (May 4, 2010). Interview with James Fishkin, Stanford University. Retrieved March 25th, 2013, from http://www.youtube.com/watch?v=da5Irgz3qpk

Youtube.com. (February 14, 2010). BYU scientist speaks out against HJR 012. Retrieved March 29th, 2013, from http://www.youtube.com/watch?v=nhxcJDctb-8 